\title{
Effect of bryostatin-1 as an anthelmintic drug on adult Syphacia muris infection in rats
}

\author{
Samar Fouad Harras ${ }^{1}$, Mohamed Hassan Mona', Aisha Gadafi Abdalla',2 and Elsayed Ibrahim Salim*
}

\begin{abstract}
Background: The fact that many laboratory rodent colonies were found to be parasite contaminated suggests a need for eradication to improve their quality for research and testing. However, the most anthelmintic are poisonous, and their application always entails some hazards to the host and interferes with the interpretation of the final results. The use of bryostatin as a potential anthelmintic drug is still a matter of controversy. Therefore, the present work was designed to examine the naturally extracted product bryostatin-1 from a marine bryozoan as a possible anthelmintic agent against Pinworms Syphacia muris.

Results: Light and scanning electron microscopy revealed normal appearance of worms collected from the infected groups with S. muris and untreated by bryostatin-1, while those collected from the bryostatin-1 treated rats revealed drastic morphological changes in the mouth parts, anus, and cuticle of all treated worms. Significant effects of bryostatin-1 on Syphacia infection were also detected in rats regarding the final body weights, average food consumption, and organ weights. Moreover, the drug has also improved the serum biochemical changes significantly in the infected rats nearly to the normal levels.

Conclusions: The study has provided morphological evidence of obvious effect of bryostatin-1 on the movement and feeding behavior of the parasite that lead to consequent weakness and death as well as improvement of the biochemical changes in the infected rats. The present study concluded that bryostatin-1 can be used as anthelmintic agent, although further studies are needed to insure the drug efficacy.
\end{abstract}

Keywords: Syphacia muris, Bryostatin1, Anthelmintics, SEM, Rat

\section{Background}

Experimental rats and mice are usually infected with pinworms of the species Syphacia muris (order: Oxyurina). They are diverse nematode worms of main health concern (Khalil, Lashein, Morsy, \& Abd El-Mottaleb, 2014). The direct transmission of these gastrointestinal (GI) nematodes by contaminated food, water, and bedding leads to continual exposure to the parasite, making the control of pinworms in animal holdings quite difficult (Taffs 1976). Syphacia muris commonly infects rats in laboratories at high prevalence even in well managed habitats (Perec-Matysiak, Okulewicz, Hildebrand, \& Zalesny,

\footnotetext{
* Correspondence: elsalem_777@yahoo.com;

elsayed.salim@science.tanta.edu.eg

'Zoology Department, Faculty of Science, Tanta University, Tanta 31527,

Egypt

Full list of author information is available at the end of the article
}

2006) and can interfere with the development of unrelated biological disorders (Trelis, Cortés, Fried, Marcilla, Esteban, et al., 2013). Screening for compounds of natural sources for anthelmintic activity, remains take great interest of scientists despite extensive use of synthetic chemicals in modern clinical practices all over the world (Verma, Gaherwal, Kanhere, \& Prakash, 2014).

Problems have emerged with the use of anthelmintics, notably the chemical residue and toxicity problems (Waller \& Prichard, 1985), as well as development of resistance in helminthes to various anthelmintic compounds and classes (Gaherwal \& Prakash, 2009).

Many groups of invertebrates produce specific substances that serve as defensive agents against predators, parasites, and infections and/or chemicals for intraspecific and interspecific communication. Some of these compounds have interesting properties which could 
potentially be exploited in pharmacology (Prinsep, Yao, Nicholson, \& Gordon, 2004). Organic compounds from marine organisms have been used extensively in the treatment of many diseases and perform as important compounds both in their natural form and as templates for synthetic modifications (Hrckova \& Velebny, 2013).

Bryostatins are among the most important compounds extracted from marine bryozoans Bugula neritina (Schmidt, 2005; Mayer \& Gustafson, 2008). To date many different bryostatins (bryostatin-1, bryostatin-2, bryostatin-7, bryostatin-9, bryostatin-16, and others) have been isolated (Hale \& Manviazar, 2010). Bryostatins are potent modulators of protein kinase C. Some recent researches showed that bryostatins exert medicinal properties such as in vitro anti-cancer activity (Kollar, Rajchard, Balounová, \& Pazourek, 2014), anti-traumatic brain injury (Zohar, Lavy, Zi, Nelson, Hongpaisan, et al., 2011), anti-depression, anti-Alzheimer's disease, and other CNS disorders (Sun \& Alkon, 2006; Paul, Arthur, Ritson-Williams, Ross, \& Kotty, 2007) and can activate innate immunity (Ariza, Ramakrishnan, Singh, Chauhan, Nagarkatti, et al., 2011). Currently, they are under investigation as anti-cancer agents, anti-AIDS/HIV agents, and memory-enhancing agents (Kollar et al., 2014). Among them, bryostatin-1 is a macrolytic lactone (ML) which is a series of cyclic macrolides, and it was postulated to be produced by a bacterial symbiont of the bryozoan (Mayer \& Gustafson, 2008).

The macrolytic lactones (MLs, macrolides) are the major class of anthelmintic drugs selected only to nematode and arthropods (Shoop, Egerton, Eary, \& Suhayda, 1990). They consist of two closely related chemical groups isolated from a natural source: avermectins and milbemycins. The avermectins include ivermectin and its derivatives: doramectin and eprinomectin. Moxidectin is the only milbemycin. Discovery of ivermectins as natural compounds has enlarged the group of anthelmintic drugs indicated primarily for use in veterinary medicine (Schoenian, 2010). Drug treatment necessitates a thorough knowledge of the life cycle of the parasites, as well as its physiology and biochemistry and surface architecture of the worm (cuticle). The worm surface, as well as mouth and gut, is the route of drug absorption. To the best of our knowledge, no previous studies were done on using bryostatin-1 as an anthelminthic drug for Syphacia muris to date. Therefore, the present work was designed.

The bryozoan Bugula neritina is widely distributed throughout the warmer waters of the world (Ryland, 1965). In Egypt, the species was previously recorded from Alexandria (Ghobashy, 1976; El-Komi, 1998), from the Suez Canal (Ghobashy, El-Komy, \& Ramadan, 1980) and from Abu Qir harbour (Abdel-Salam \& Ramadan, 2008). Approximately 16 drugs have been successfully developed from marine sources in China, and 15,000 compounds have been isolated in the USA (Molinski, Dalisay, Lievens, \& Saludes, 2009).

The aim of this study was to throw light on the possible potential of bryostatin- 1 as an anthelmintic drug in experimentally infected rats with Syphacia muris using SEM, with special concern to its safety and side effects on blood biochemistry.

\section{Methods \\ Experimental animals}

Healthy male Wistar rats, 5-6 weeks old, were obtained from the Holding Company for Biological Products and Vaccines (Vaccera), Helwan, Egypt, and were allocated to dielectric polymer cages with wood chips for bedding and allowed to acclimate for 1 week in the animal facility conditions before experimentation. The institutional animal care and use facility and the Zoology Department's council of the Faculty of Science, Tanta University, Egypt, approved the experimental design. The animals were kept in laboratory at slandered condition protocol of temperature and humidity at $22 \pm 3{ }^{\circ} \mathrm{C}$ and $55 \pm 5 \%$ respectively. The lighting was $12 \mathrm{~h} / 12 \mathrm{~h}$ light-dark cycle. Animals' body weights, food consumption, and water intakes were measured precisely every week, and the average was calculated at the end of the experiment as grams/ rat/day. Only those animals which were not having any kind of helminthic infection confirmed by negative microscopical examination of the stool were selected. These were kept in sterilized cages with the same dry husk padding and were fed daily with the standard diet and offered drinking water. Uninfected control rats were kept in strictly specific-pathogen-free (SPF) clean room.

\section{Bryostatin-1 as a tested drug}

Bryostatin-1, a macrolactone isolated from the marine bryozoan, Bugula neritina, with purity $\geq 99 \%$ (solid) was purchased from Sigma-Aldrich, USA (cat. no. B7431). Every $10 \mu \mathrm{g}$ of bryostatin were dissolved in $1 \mathrm{ml} 70 \%$ HPLC pure ethanol according to the manufacturer's manual as a stock solution. Each rat was injected intravenously twice through the caudal vein, once a week apart, with $5 \mu \mathrm{g} / \mathrm{kg}$ body weight of bryostatin-1 (Jiangbo, Xuying, Yuping, Xili, Yiwen, et al., 2010).

\section{Maintenance and infection protocol of Syphacia muris}

Helminth-free rats were put into cages containing rats infected with $S$. muris to insure the infection. After 1 day, the experimental rats were removed to their own cages, and their stool were examined every day for the presence of $S$. muris eggs for 7 days; the same process of infection was repeated for additional group of rats.

All animals were sacrificed 7 to 9 days after observing the eggs. The gravid pinworms collected and their eggs 
were incubated for $4-6 \mathrm{~h}$ at $37{ }^{\circ} \mathrm{C}$ in a $0.8 \%$ saline solution to become sufficiently embryonated and continue developing to the infective stage (Stahl, 1963).

Thirty rats were orally inoculated with 80 to 100 eggs via a stomach tube. The rats were left to complete a direct cycle of the parasite which required only 11-15 days (Levine, 1968).

\section{Experimental groups}

A total of 45 rats were randomly divided into three equal groups, five rats each:

Group (I): healthy control uninfected rats

Group (II): infected with S. muris and were not treated by bryostatin-1

Group (III): infected with S. muris and treated by bryostatin-1

After 2 weeks of last treatment, all rats in the experimental groups were sacrificed under ether anesthesia according to the ethical rules for handling the experimental animals. Blood samples were collected via the abdominal aorta for estimation of total serum proteins and albumin levels using a colorimetric method. After necropsy, absolute and relative weights of the liver, kidneys, and spleen were calculated.

The alimentary canal and its off shoots of all rats including the uninfected controls were removed, while each colorectum was placed separately in a Petri dish containing $0.9 \%$ saline solution. Each colorectum was examined using binocular dissecting microscope at $\times 20$ magnification. The observed parasites were preserved in $70 \%$ ethanol at $37{ }^{\circ} \mathrm{C}$, then was transmitted to a combination of 95 portions of $70 \%$ ethanol +5 portions of glycerin at room temperature (RT). Samples were treated with glycerin or lactophenol for 2 min, mounted, and enclosed with shield glass and taped up with a slide sealing compound.

For the scanning electron microscopy (SEM) investigation, 40 specimens for both untreated and treated worms were fixed in cold 3\% phosphate-buffered gluteraldhyde, post fixed in $1 \%$ osmium tetroxide, critical point dried, and coated with gold, and 10 from each of the group out of the 40 fixed specimens were examined and photographed using a JEOL 5300 JSM scanning electron microscope at an accelerating voltage of 25 and $30 \mathrm{kV}$.

\section{Statistical analysis}

The data obtained in the present work were represented in tables as means \pm standard deviation (S.D.). The significance of differences between the data means were calculated according to the Student $t$ test, and the statistical significance was indicated at $P<0.05$.

\section{Results}

Light and scanning electron microscopy of untreated Syphacia muris

Syphacia muris worms recovered from infected bryostatin-1-untreated rats are small worms and clear white when alive which possess a narrow pointed posterior extremities. Light and SEM investigation revealed that the cephalic plate was quadrate in shape while the triradiate mouth opening was small and surrounded by three equal sized fleshy lips (one dorsal and two ventrolateral). The buccal cavity leads to the esophagus which is divided into an anterior cylindrical part and a characterized bulb. The cervical alae are small, striated in continuity with the longitudinal body cuticular striation. The anal opening lies in the posterior extremity of the body (Fig. 1).

\section{Scanning electron microscopy of treated Syphacia muris}

Treatment of $S$. muris worms with bryostatin-1 leads to drastic morphological changes in the mouth parts, anus, and cuticle of $90 \%$ of the 10 examined worm. The changes were confined to morphological disfigurements of the three lips with loss of normal aspects. The indistinct three lips showed scattered blebs on it. The cervical alae showed multiple uniform blebbing distribution. The cuticle appeared more swollen than normal and lost its normal characteristics with longitudinal wrinkled and corrugated appearance. The anus was bloated with food and protruded outside with herniation of its internal content (Fig. 2).

\section{Body and organ weights and average food consumption}

As shown in Table 1, S. muris-infected rats of group (GII) had significant reduction in their body weights when compared with the uninfected control group $(P=$ $0.0004)$. Treatment of rats infected with $S$. muris by bryostatin-1 in group (GIII) has significantly improved their body weights as compared to group (GII) $(P=$ 0079). Food consumption was also significantly improved in the bryostatin-1-treated rats as compared to the infected untreated group (GII) $(P=0.013)$, which has almost reached the control levels. Absolute and relative liver, kidney, and spleen weights were not significantly changed among the experimental groups $(P>0.05)$.

\section{Total proteins and albumin levels}

As shown in Table 2, the average serum total protein levels were significantly higher in the infected untreated group (GII) as compared with control group (GI) $(P=$ $0.0025)$. Treatment of infected rats with bryostatin- 1 in group (GIII) has increased serum protein levels above that of untreated group (GII) $(P=0019)$ and rendered it to almost control levels $(P=0.147)$ in infected group (group III). Serum albumin levels in group II decreased 

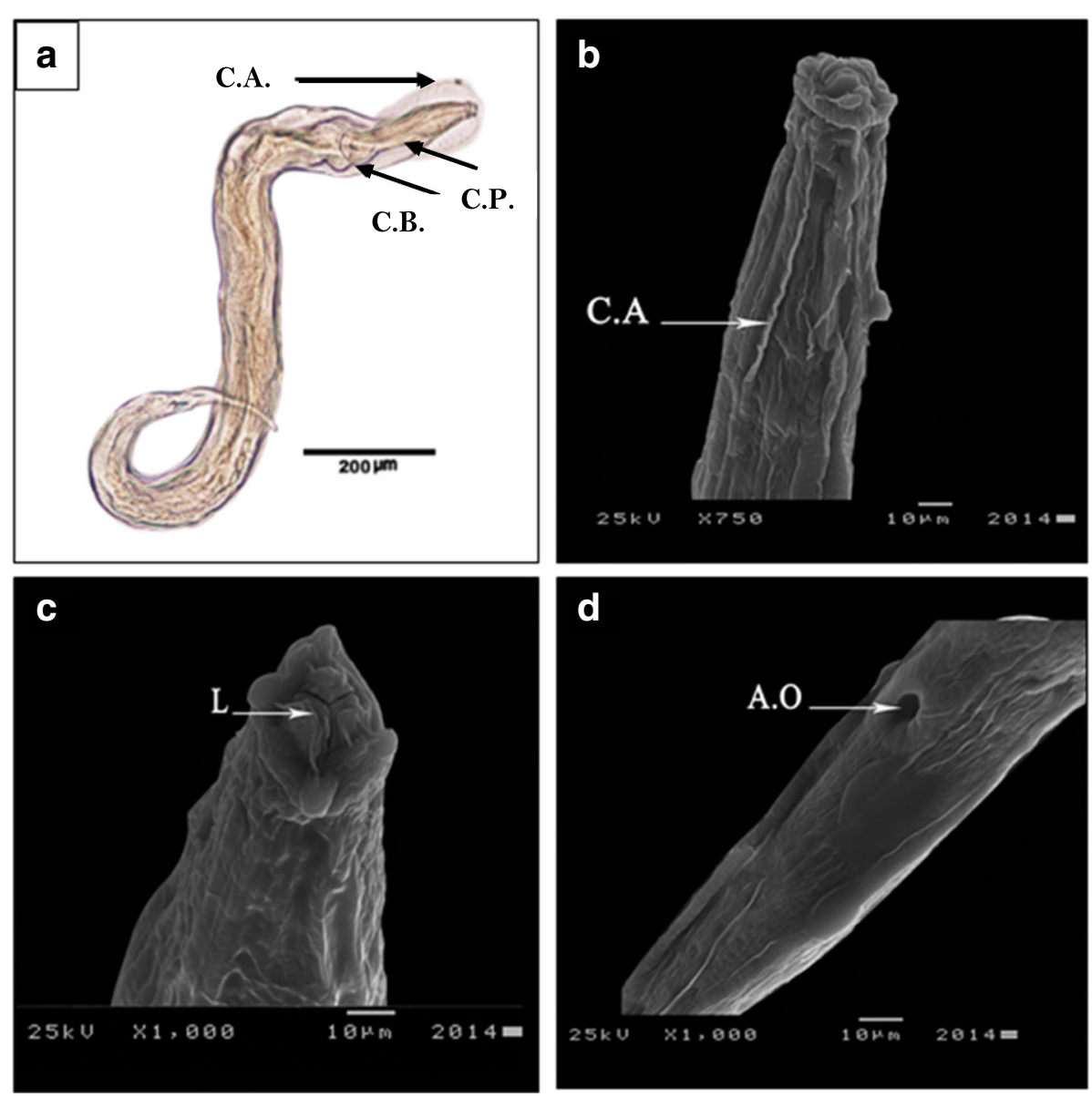

Fig. 1 a-d Photomicrographs of control female Syphacia muris. a Light microscope photomicrograph of unstained whole mount worm showing general architecture, cervical alae (C.A), cylindrical part (C.P.), and a characterized bulb of the esophagus (C.B.). ×40. b, c Scanning electron micrographs for the surface topography of the anterior end showing the mouth with three equal fleshy lips $(L)$ and cervical alae $(C . A)$ from the anterior extremity. SEM, magnifications are $\times 750$ and $\times 1000$ respectively. $\mathbf{d}$ Normal anal opening (A.O) of the worm. SEM, magnification $\times 1000$

significantly than those in groups I $(P=0.012)$ and III $(P=0.029)$. No statistical differences were observed in these levels between groups I and III $(P=0.57)$.

\section{Discussion}

Bryostatins are marine natural products with chemical structure of macrolide lactones, one of a series of cyclic macrolides, isolated from Bryozoan Bugula neritina (Pettit, Herald, Doubek, Herald, Arnold, et al., 1982). The most frequently investigated substance is bryostatin-1, which is a highly oxygenated macrolide with a polyacetate backbone (Davidson, Allen, Lim, Anderson, \& Haygood, 2001). In vitro studies indicated that bryostatin-1 and its synthetic analogues as modulators of protein kinase $\mathrm{C}$ (PKC) thus may play a crucial event in tumor promotion and as a potential drug for treatment of many diseases including cancer (Kollar et al., 2014). However, its use as a potential anthelmintic drug is still a matter of controversy and has not been extensively investigated. The present study was undertaken to demonstrate the direct effect of intravenously injected bryostatin-1 on cuticular structure of Syphacia muris in experimentally infected rats. To the best of our knowledge, there is no available literature dealing with the assessment of the impact of bryostatins on Syphacia muris using scanning electron microscopy which could support our postulation.

Previous studies on bryostatin-1 distribution injected intravenously (i.v.) or intraperitoneally (i.p.) in mice by using a radioactive substance have been reported by Sun and Alkon (2006). They revealed a wide distribution of the drug with high levels in lungs, liver, gastrointestinal tract, and fat. As the cuticle of gastrointestinal nematodes is metabolically active and morphologically specialized for selective absorption of nutrients and osmoregulation, the passive diffusion of anthelmintics through the cuticle (Alvarez, Mottier, \& Lanusse, 2007), it would be probably responsible for the detected changes and deformation of the parasite body surface.

In this study, the SEM of treated Syphacia muris revealed dramatic changes compared to that of active 

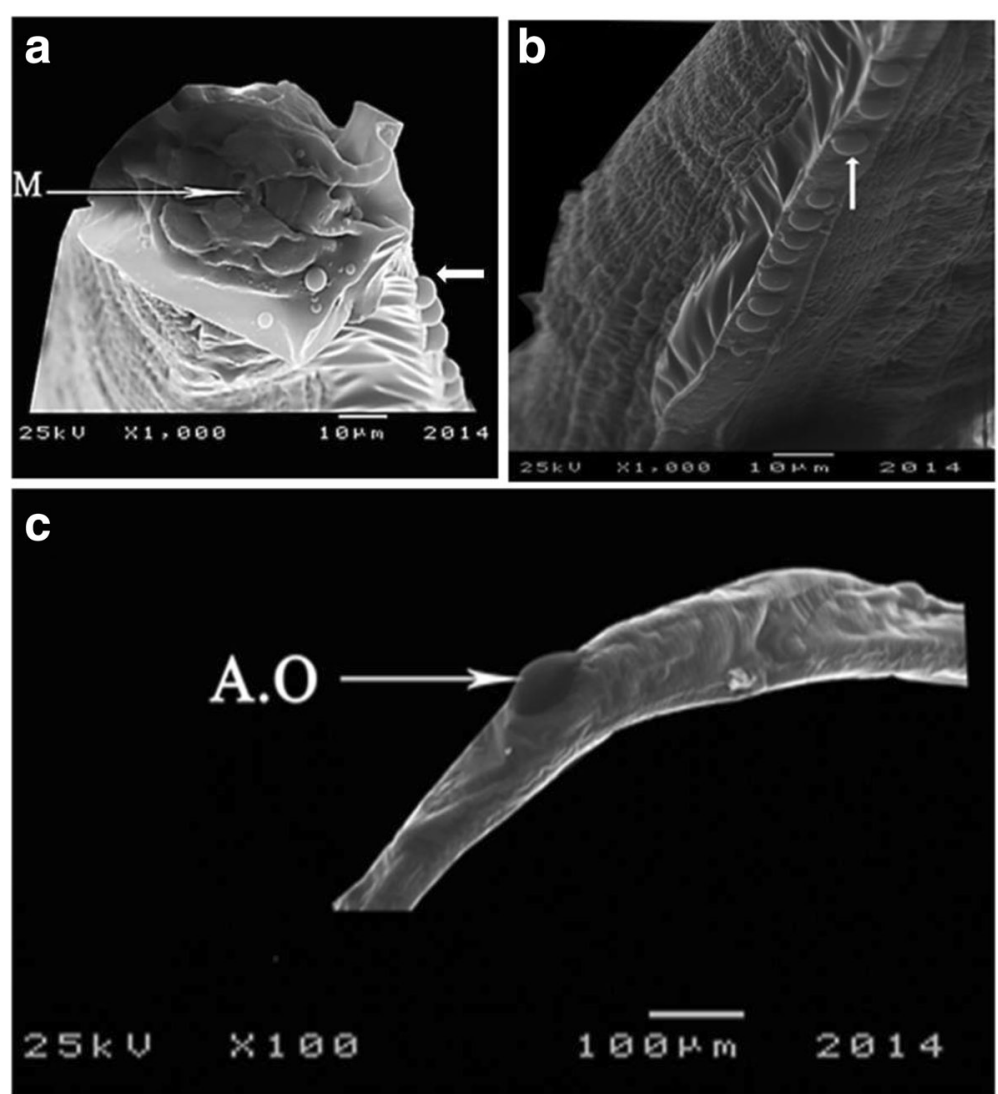

Fig. 2 a-c Scanning electron micrographs of the surface topography (SEM) of a bryostatin-1 treated female Syphacia muris. a, b Morphology of the anterior end showing mouth (M) surrounded by indistinct three lips with scattered blebs and multiple uniform blebbings on the cervical alae (arrow). SEM, magnification $\times 1000$. c Anal opening (A.O) bloated with food. SEM, magnification $\times 100$

untreated worms isolated from the infected rats under study. All changes observed in the present treated parasite may reflect neuromuscular disturbances that affect motility and feeding mechanisms, as well as the ability of worm to contract its enteric muscle to expel stool outside the body. The observed distributed blebs arranged along the cervical alae almost due to the nerve ending inflammation as confirmed by Schoenian (2010) who reported that all of macrolytic lactones with the same mode of action act as $\gamma$-aminobutyric acid (GABA) antagonist in nematodes. They interfere with GABAmediated neurotransmission causing malfunction and paralysis or may lead to death of the parasite. GABA neurons were identified by immunostaining methods (Guastella, Johnson, \& Stretton, 1991), and their functions were then identified by McIntire, Jorgensen, and

Table 1 Statistical comparisons of the final body, absolute, and relative (\%) organ weights and food consumption ( $\mathrm{g} / \mathrm{rat} / \mathrm{day}$ ) between the three experimental groups

\begin{tabular}{|c|c|c|c|c|c|c|c|c|}
\hline Groups & Treatment & No. of rats & $\begin{array}{l}\text { Final body } \\
\text { weights (g) }\end{array}$ & Liver wt. (\%) & $\begin{array}{l}\text { Right kidney } \\
\text { wt. (\%) }\end{array}$ & $\begin{array}{l}\text { Left kidney } \\
\text { wt. (\%) }\end{array}$ & Spleen wt. (\%) & $\begin{array}{l}\text { Avr. food } \\
\text { consumption } \\
\text { (g/rat/day) }\end{array}$ \\
\hline$\overline{\mathrm{Gl}}$ & Control & 15 & $160.0 \pm 3.22^{\mathrm{a}}$ & $5.12 \pm 1.3(3.2)^{b}$ & $0.59 \pm 0.12(0.37)$ & $0.59 \pm 0.13(0.37)$ & $0.61 \pm 0.25(0.38)$ & 12 \\
\hline Gll & S. muris infection & 15 & $133.7 \pm 3.08$ & $4.7 \pm 1.3(3.2)$ & $0.47 \pm 0.12(0.37)$ & $0.47 \pm 0.13(0.37)$ & $0.65 \pm 0.42(0.38)$ & 8.9 \\
\hline GIII & S. muris + bryostatin 1 & 15 & $146.8 \pm 2.4$ & $7.1 \pm 2.9(5.3)$ & $0.57 \pm 0.01(0.43)$ & $0.55 \pm 0.03(0.41)$ & $0.64 \pm 0.87(0.48)$ & 11.5 \\
\hline \multirow[t]{3}{*}{$P$ value } & P1 & & $0.0004^{*}$ & 0.477 & 0.118 & 0.155 & 0.831 & $0.001^{*}$ \\
\hline & P2 & & $0.0079^{*}$ & 0.057 & 0.096 & 0.185 & 0.934 & $0.013^{*}$ \\
\hline & P3 & & $0.0015^{*}$ & 0.204 & 0.542 & 0.520 & 0.811 & 0.394 \\
\hline
\end{tabular}

* $P$ values below $0.05(P<0.05)$ are significant

${ }^{a}$ Means \pm SD

${ }^{b}$ Values between brackets are relative organ weights (organ weight/body weight $\times 100$. $P 1$ GI vs GII, $P 2$ GII vs GIII, P3 GI vs GIII 
Table 2 Statistical comparisons of serum total proteins $(\mathrm{g} / \mathrm{dl})$ and albumin $(\mathrm{g} / \mathrm{dl})$ levels between the three experimental groups

\begin{tabular}{lllll}
\hline Groups & Treatment & No. of samples $(n)$ & Total protein $(\mathrm{g} / \mathrm{dl})$ & Albumin $(\mathrm{g} / \mathrm{dl})$ \\
\hline GI & Control & 5 & $6.9 \pm 0.54^{\text {a }}$ & $4.8 \pm 0.6$ \\
GII & S. muris infection & 5 & $9.03 \pm 1.2$ & $3.7 \pm 0.7$ \\
GIII & S. muris + bryostatin-1 & 5 & $7.4 \pm 0.4$ & $4.6 \pm 0.6$ \\
$P$ value & P1 & & $0.0025^{*}$ & $0.012^{*}$ \\
& P2 & & $0.0019^{*}$ & $0.029^{*}$ \\
& P3 & & 0.147 & 0.57 \\
\hline
\end{tabular}

$P 1 \mathrm{Gl}$ vs Gll, $P 2 \mathrm{Gll}$ vs GIII, $P 3 \mathrm{Gl}$ vs GIII

* $P$ values below $0.05(P<0.05)$ are significant

${ }^{\text {a }}$ Means \pm SD

Horvitz (1993) who concluded that GABA acts as both inhibitory and excitatory neurotransmitters. The inhibitory GABA functions are essential for locomotion and feeding while the excitatory neurotransmitters are needed for defecation.

Jorgensen (2005) reported that, in contrast to vertebrates when GABA acts at synapses of the central nervous system, in nematodes, GABA acts primarily at neuromuscular synapses. Specially, GABA acts to relax the body muscles during locomotion and for aging and contract the enteric muscles during defecation. Therefore, the present observation can be attributed to the fact that upon lacking GABA transmitters, the body shrinks; that is, it pulls in its head and shortens its body due to hypercontractions on the body wall muscles on both sides with inability of the head to restore its position and the worm fails to contract its enteric muscles and becomes bloated with food.

The present results also come in accordance with the suggestion of Martin and Pennington (1988) who reported that all macrolytic lactones have receptormediated effect on glutamate-gated chloride (Glucl) ion channels which has been directly correlated to nematocidal activity and considered as their major mode of action. Moreover, it can be mentioned that the effect of bryostatin is similar to some extent with the effect of avermectin (macrolytic lacton derivative) which is considered as the most effective and safe anthelmintic drug. It was described by Prichard, Ménez, and Lespine (2012) to be involved in the opening of the GABA-dependent chloride channels, inducing the release of chloride into the muscle cells resulting in inhibition of contraction leading to the complete paralysis and immobilization of the worm. Thus, to the best of our knowledge, the herein SEM observation is used for the first time to evaluate bryostatin-1 as anthelmintic agent which is strengthened by the morphological changes observed on S. muris cuticular architecture.

It could be postulated that infection with pinworms in general is considered to be non- or mildly pathogenic in animal with normal immune system (Harkness \&
Wagner, 1995). While S. muris infection of rat colonies is usually subclinical rectal prolapse, intussusception, fecal impaction, rough hair coat, and poor weight gain have been reported in heavily infected rodents (Baker, 1998). In addition, the author has mentioned that very heavy parasite loads may lead to catarrhal enteritis, liver granuloma, and perianal irritation. Consequently, in the present study, rats experimentally infected with $S$. muris showed significant reduction in food consumption and significant reduction of body weights, while there were non-significant alternation in both absolute and relative weights of body organs as compared to normal uninfected rats.

The definite weight differences between treated and untreated groups observed in this study may have probably arose from the reduction in the food consumption. These results are in accordance with Wagner (1988) who reported that $S$. muris experimentally infected rats grew slower than uninfected ones. In addition, Lübcke, Hutchenson, and Barbezat (1992) reported that parasitism by $S$. muris influences intestinal electrolyte transport by decreasing the net absorption of $\mathrm{Na}^{+}, \mathrm{Cl}^{-}$, and water in infected rats, despite the absence of apparent histological changes. Other researches have explained the association between malnutrition and intestinal nematode by the anorexia that they cause and a variety of pathophysiological responses in gastrointestinal tract such as vomiting, diarrhea, and impaired digestion and absorption (Koski \& Scott, 2001). Altogether, these alternations deleteriously affect the host ability to get enough nutrients from diet.

It has been reported by Gay, Fioramonti, Garcia-Villar, and Bueno (2000) that under the influence of heavy intestinal parasitic infection, the gut motility modifies and the peristalsis generally slows down unless diarrhea occurs at the same time. Worm's toxins stimulate the production of gastrointestinal hormones like gastrin and cholecystokinin causing reduction of voluntary feed intake, as well as helminthes developing in the animal may cause local lesions and changes in plasma proteins (Fekete \& Kellems, 2007). Moreover, the parasite 
burdens during short-term exposure of uninfected rats to eggs of pinworms were higher than in long-term exposure (Sato, Ooi, Nonaka, Oku, \& Kamiya, 1995).

In the present study, $S$. muris infection in rats showed marked effect on serum proteins (after 12 weeks from infection). There was significant increase in the total protein levels with significant reduction in serum albumin in infected rats when compared to uninfected ones. It is likely that the increase in total proteins may have been due to increased mass of parasite proteins as a result of growing infection or possibly increases in parasite derived intracellular enzymes and proteins as the parasites are lysed by the host immune system (Orhue, Nwanze, \& Okafor, 2005). A drop in serum albumin level is usually the result of deceased protein synthesis by the liver or increased protein loss through the gut or the kidney. Other possible cause of decrease in albumin may include malabsorption and increased protein need secondary to infection (Orhue et al., 2005).

Moreover, serum protein changes can be explained by the fact that during the acute phase response to infection starting with anorexia, the concentration of a group of proteins named acute phase reactant (APR) proteins including $\mathrm{C}$ reactive protein, ceruloplasmin, complement system, and proinflammatory cytokines are strikingly increased (Jones \& Symonds, 1982; Heegaard, Godson, Toussaint, Toornehooj, Larsen, et al., 2000). The biological role of the APR is to combat in repair tissue damages and stimulate immune response. Strong peripheral protein catabolism will occur to supply amino acids for the acute phase protein synthesis in the liver with concomitant reduction in albumin synthesis (Schreiber, Nagashima, Martin, \& Kotler, 1982).

After 4 weeks of intravenous (i.v.) bryostatin-1 inoculation ( 2 doses, 1 week apart) of the infected rats in the present study, an improvement in food consumption was observed with subsequent improvement in the body weights, total serum proteins, and albumin concentration to levels comparable to that of uninfected control rats. These results may denote that these changes are reversible and improvement occurred after bryostatin-1 treatment support our postulation. As regards the organ weights, the present study revealed no significant changes in absolute and relative weights of the liver, kidney, and spleen among the experimental groups. These results denote a safe effect with no toxicity results by using bryostatin as an anthelmintic drug.

SEM observation in the present study provided morphological evidence of destructive effect of bryostatin-1 affecting movement and feeding behavior of the parasite that could lead to their weakness and death as well as improvement of the biochemical changes in the infected rats. Thus, the study leads to conclusion that bryostatin can be used as anthelmintic agent beside its effect on other diseases.

\section{Conclusions}

However, in addition to our final conclusion, further studies are needed to measure the bryostatin-1 efficacy on the basis of reduction in the worm burden and to evaluate its safety for the host to insure adequate dosing and confirm its general anti-parasitic effects.

\section{Acknowledgements \\ Not applicable \\ Funding \\ This research received no specific grant from any funding agency.}

\section{Availability of data and materials}

The healthy Wistar rats were obtained from Holding Company for Biological Products and Vaccine (Vaccera), Helwan, Egypt. While Bryostatin-1 was purchased from Sigma-Aldrich, USA (cat. No. B7431).

\section{Authors' contributions}

MHM, EIS, and SFH conceived and designed study. SFH and AGA participated in the experimental study and acquisition of data. MHM, EIS, SFH, and AGA analyzed and/or interpreted the data. SFH drafted the manuscript. MHM and EIS critically revised the manuscript for important intellectual content. All authors read and approved the final manuscript.

\section{Ethics approval}

We have got an ethical approval from Zoology Department, Faculty of Science, Tanta University, according to the ethical rules for handling the experimental animals. Since the ethical committee of our faculty is not established yet, we promise to send it immediately after finishing the requirements.

\section{Consent for publication}

Not applicable

\section{Competing interests}

The authors declare that they have no competing interests.

\section{Publisher's Note}

Springer Nature remains neutral with regard to jurisdictional claims in published maps and institutional affiliations.

\section{Author details}

'Zoology Department, Faculty of Science, Tanta University, Tanta 31527, Egypt. ${ }^{2}$ Faculty of Public Health, Benghazi University, Benghazi, Libya.

Received: 14 June 2017 Accepted: 23 November 2017

Published online: 20 December 2017

\section{References}

Abdel-Salam, K. M., \& Ramadan, S. E. (2008). Fouling Bryozoa from some Alexandria harbours, Egypt. (I) Erect species. Mediterranean Marine Science, 9, 31-47.

Alvarez, L. I., Mottier, M. L., \& Lanusse, C. E. (2007). Drug transfer into target helminth parasites. Trends in Parasitology, 23, 97-104.

Ariza, M. E., Ramakrishnan, R., Singh, N. P., Chauhan, A., Nagarkatti, P. S., \& Nagarkatti, M. (2011). Bryostatin-1, a naturally occurring antineoplastic agent, acts as a toll-like receptor 4 (TLR-4) ligand and induces unique cytokines and chemokines in dendritic cells. The Journal of Biological Chemistry, 286, 24-34.

Baker, D. G. (1998). Natural pathogens of laboratory mice, rats, and rabbits and their effects on research. Clinical Microbiology Reviews, 11, 231-266.

Davidson, S. K., Allen, S. W., Lim, G. E., Anderson, C. M., \& Haygood, M. G. (2001). Evidence for the biosynthesis of bryostatins by the bacterial symbiont "Candidatus Endobugula sertula" of the bryozoan Bugula neritina. Applied and Environmental Microbiology, 67, 4531-4537. 
El-Komi, M. M. (1998). Dynamics of the buoys macrofouling communities at Alexandria harbour, Egypt. J Egypt Ger Soc Zool B - Vertebrate Anatomy \& Embryology, 25, 259-281.

Fekete, S. G., \& Kellems, R. O. (2007). Interrelationship of feeding with immunity and parasitic infection: A review. Vet Med-Czech., 52, 131-143.

Gaherwal, S., \& Prakash, M. M. (2009). The protective role of lymphocyte in helminthic infection. Indian Res Comm, 3, 54-55.

Gay, J., Fioramonti, J., Garcia-Villar, R., \& Bueno, L. (2000). Development and sequels of intestinal inflammation in nematode-infected rats. Role of mast cells. Neurogastroenterology and Motility, 8, 171-178.

Ghobashy, A. F. A. (1976). Seasonal variation and settlement behavior of the principal fouling organisms in the eastern harbour of Alexandria, (pp. 213220). Juan-Les- Pins, Antibes: Proceeding 4th international Congress on Marine Corrosion \& Fouling.

Ghobashy, A.F.A, El-Komy, M.M., Ramadan, S.E., 1980. Fouling in the Suez Canal. Proceeding 5th International Congress on Marine Corrosion \& Fouling, Marine Biology; Madrid. 75-92.

Guastella, J., Johnson, C. D., \& Stretton, A. O. W. (1991). GABA-immunoreactive neurons in the nematode Ascaris. The Journal of Comparative Neurology, 307, 584-597.

Hale, K. J., \& Manviazar, S. (2010). New approaches to the total synthesis of bryostatin antitumor macrolides. Chemistry, an Asian Journal, 5, 704-754.

Harkness, J. E., \& Wagner, J. E. (1995). The biology and medicine of rabbits and rodents, (4th ed., ). Baltimore: Williams and Williams.

Heegaard, P. M., Godson, D. L., Toussaint, M. J., Toornehooj, K., Larsen, L. E., Viuff, B., \& Rønsholt, L. (2000). The acute phase response of haptoglobin and serum amyloid A (SAA) in cattle undergoing experimental infection with bovine respiratory syncytial virus. Veterinary Immunology and Immunopathology, 77, 151-159.

Hrckova, G., \& Velebny, S. (2013). Parasitic helminths of humans and animals. Pharmacological Potential of Selected Natural Compounds in the Control of Parasitic Diseases, 2, 29-99.

Jiangbo, Z., Xuying, W., Yuping, Z., Xili, M., Yiwen, Z., \& Tianbao, Z. (2010). Toxicity of bryostatin-1 on the embryo-fetal development of Sprague-Dawley rats. Birth Defects Res. B., 89, 171-174.

Jones, W., \& Symonds, L. E. A. (1982). Protein synthesis in the whole body, liver, skeletal muscle and kidney cortex of lambs infected by the nematode Trichostrongylus colubriformis. Mt J Parasitol., 12, 295-301.

Jorgensen, E., 2005. GABA. Worm book ed. The C. elegans research community, WormBook, doi:10.1895/wormbook.1.14.1, http://www.wormbook.org.

Khalil, A. I., Lashein, G. H., Morsy, G. H., \& Abd El-Mottaleb, D. I. (2014). Oxyurids of wild and laboratory rodents from Egypt. Life Sciences, 11, 94-107.

Kollar, P., Rajchard, J., Balounová, Z., \& Pazourek, J. (2014). Marine natural products bryostatins in preclinical and clinical studies. Pharmaceutical Biology, 52, 237-242.

Koski, K. G., \& Scott, M. E. (2001). Gastrointestinal nematodes, nutrition and immunity: Breaking the negative spiral. Annual Review of Nutrition, 21, 297321.

Levine, N. D. (1968). Nematode parasites of domestic animals and man, (p. 600). Minneapolis: Burgess publishing company.

Lübcke, R. F., Hutchenson, A. R., \& Barbezat, G. O. (1992). Impaired intestinal electrolyte transport in rats infested with the common parasite Syphacia muris. Digestive Diseases and Sciences, 37, 60-64.

Martin, R., \& Pennington, A. J. (1988). Effect of dihydroavermectin B1a on chloridesingle-channel currents in Ascaris muscle. Pesticide Science, 24, 90-91.

Mayer, A. M., \& Gustafson, K. R. (2008). Marine pharmacology in 2005-2006: Antitumour and cytotoxic compounds. European Journal of Cancer, 44, 2357-2387.

McIntire, S. L., Jorgensen, E., \& Horvitz, H. R. (1993). Genes required for GABA function in Caenorhabditis elegans. Nature, 364, 334-337.

Molinski, T. F., Dalisay, D. S., Lievens, S. L., \& Saludes, J. P. (2009). Drug development from marine natural products. Nature Reviews. Drug Discovery, 8, 69-85.

Orhue, N. E. J., Nwanze, E. A. C., \& Okafor, A. (2005). Serum total protein, albumin and globulin levels in Trypanosoma brucei infected rabbits: Effect of orally administered Scoparia dulcis. African J Biotechnol., 4, 1152-1155.

Paul, V. J., Arthur, K., Ritson-Williams, R., Ross, C., \& Kotty, S. (2007). Chemical defenses: From compounds to communities. The Biological Bulletin, 213, 226-251.

Perec-Matysiak, A., Okulewicz, A., Hildebrand, J., \& Zalesny, G. (2006). Helminth parasites of laboratory mice and rats. Wiadomości Parazytologiczne, 52, 99-102.

Pettit, G., Herald, C., Doubek, D., Herald, D., Arnold, E., \& Clardy, J. (1982). Isolation and structure of bryostatin 1. Journal of the American Chemical Society, 104, 6846-6848

Prichard, R., Ménez, C., \& Lespine, A. (2012). Moxidectin and avermectins: Consanguinity but not identity. Int J Parasitol Drugs Drug Resist., 2, 134-153.
Prinsep, M. R., Yao, B., Nicholson, B. K., \& Gordon, D. P. (2004). The pterocellins, bioactive alkaloids from the marine bryozoan Pterocella vesiculosa. Phytochemistry Reviews, 3, 325-331.

Ryland, J. S. (1965). Catalogue of the main marine fouling organisms (found on ships coming into European waters), (vol. 2, p. 83). Paris: Polyzoa. Organisation for Economic Co-operation and Development.

Sato, Y., Ooi, H. K., Nonaka, N., Oku, Y., \& Kamiya, M. (1995). Antibody production in Syphacia obvelata infected mice. The Journal of Parasitology, 8, 559-562.

Schmidt, E. W. (2005). From chemical structure to environmental biosynthetic pathways: Navigating marine invertebrate-bacteria associations. Trends in Biotechnology, 23, 437-440.

Schoenian, S, 2010. Understanding anthelmintics. Anthelmintic drugs-Wormbook.

Schreiber, H., Nagashima, M., Martin, A., \& Kotler, L. (1982). The acute phase response of plasma protein synthesis during experimental inflammation. The Journal of Biological Chemistry, 257, 10271-10277.

Shoop, W. L., Egerton, J. R., Eary, C. H., \& Suhayda, D. (1990). Anthelmintic activity of the macrocyclic lactone F28249-alpha in sheep. American Journal of Veterinary Research, 51, 1873-1874.

Stahl, W. (1963). Studies on the life cycle of Syphacia muris, the rat pinworm. The Keio Journal of Medicine, 12, 55-60.

Sun, M. K., \& Alkon, D. L. (2006). Bryostatin-1: Pharmacology and therapeutic potential as a CNS drug. CNS Drug Reviews, 12, 1-8.

Taffs, L. F. (1976). Pinworm infection in laboratory rodents: A review. Laboratory Animals, 10, 1-10

Trelis, M., Cortés, A., Fried, B., Marcilla, A., Esteban, J. G., \& Toledo, R. (2013). Protective immunity against Echinostoma caproni in rats is induced by Syphacia muris infection. International Journal for Parasitology, 43, 453-463.

Verma, S., Gaherwal, S., Kanhere, R. R., \& Prakash, M. M. (2014). Anthelmintic efficacy of Butea monosperma against Syphacia muris in mice. Acta Parasitol Globalis., 5, 55-58.

Wagner, M. (1988). The effect of infection with the pinworm (Syphacia muris) on rat growth. Laboratory Animal Science, 38, 476-478.

Waller, P. J., \& Prichard, R. K. (1985). Drug resistance in nematodes. In W. C. Campbell, \& R. S. Rew (Eds.), Chemotherapy of parasitic infections, (pp. 339362). New York: Phenum.

Zohar, O., Lavy, R., Zi, X. M., Nelson, T. J., Hongpaisan, J., et al. (2011). PKC activator the rapeutic for mild traumatic brain injury in mice. Neurobiology of Disease, 41, 329-337.

\section{Submit your manuscript to a SpringerOpen ${ }^{\circ}$ journal and benefit from:}

- Convenient online submission

- Rigorous peer review

- Open access: articles freely available online

- High visibility within the field

- Retaining the copyright to your article

Submit your next manuscript at $>$ springeropen.com 